Response, part of a Special Feature on Law and Social-Ecological Resilience, Part I, Contributions from Resilience 2011

\title{
Resilience and Administrative Law
}

\author{
Derek Armitage $^{1}$
}

Administrative law is a crucial variable determining how societies adapt and transform in response to linked socialecological change. Given the uncertainty that comes with the increasing scope, scale, and rapidity of change, further theorization and empirical research on administrative law is needed. Green et al. (2013) analyze the extent to which resilience-inspired principles of governance are incorporated into the design features of the EU Water Framework Directive, and in doing so they surface a question of broad importance: How can societies create enabling legal and institutional conditions that foster resilience at multiple scales (e.g., from communities to transboundary river basins) and which respond to a new generation of environmental challenges (e.g., rapid shifts in hydrological function because of climate change)?

With regard to the EU Water Directive, the authors don't provide a pathway forward, but they do point to some key issues of concern that are relevant in other contexts, such as the need for well-developed monitoring arrangements designed to provide timely feedback. And their analysis of the Water Directive opens a window on some issues and challenges of broader importance when contemplating law and resilience generally, and flexibility and enforcement, more specifically. For example, analyzing how administrative law may foster resilience requires that the normative dimensions of resilience be carefully unpacked (i.e., resilience of what, for whom, as defined by whom?). De facto assumptions about resilience as a desirable system attribute need scrutiny. Any discourse in administrative law that emphasizes building, increasing or maintaining resilience may implicitly support a notion that resilience is inherently a "good" thing. But without a space for individuals and groups to articulate a vision for the river basins in which they live, assessments about the resilience of the system may be conceptually leaky. Moreover, it is probably worth thinking about the EU Water Directive - and other examples of administrative law - not only with regard to, or through the lens of, resilience, but also with reference to adaptability (e.g., a capacity to adjust responses to continue within an envelope of water allocation and use, or current social-ecological trajectory), and transformability (the capacity to create or support the emergence of a new set of conditions in a river basin where existing conditions are untenable) (Walker et al. 2004).
Thinking about resilience and law also requires that we disentangle two related objects of analytical concern: the governing system (e.g., the EU Water Directive) and the system to be governed - in this case the river basins that serve as a focal point of the Directive. This is important because the resilience of the governing system is not necessarily positively correlated with the resilience of the system to be governed. In fact, the analysis seems to suggest some uncertainty as to whether the EU Water Directive reflects the principles of 'resilience management' (senu Walker et al. 2002) or if a lack of feedback from monitoring may overtime make the Directive more rigid, and thus, an example of 'resilient management' (that is, a situation in which the management system is resilient to change).

Two other observations about resilience and law emerge in the context of Green et al.'s analysis of the Directive. First, the Directive clearly reflects a highly formalized and codified legal and regulatory setting. But theorizing the relationship between resilience and law may benefit from examples and cases where legal pluralism - multiple, overlapping legal systems in one jurisdiction - is more common. For example, well-studied examples of customary arrangements show (despite their limits) evidence of both institutional flexibility with regard to use, protection, access, and the distribution of ecosystem services, along with legitimate and accountable mechanisms of enforcement, sanctioning and control. Lastly, I was reminded of the importance of incorporating social theory with assessments of resilience. As embodied in the principles used in Green et al.'s analysis, the application of resilience thinking can generate useful insights about the balance between regulatory flexibility and enforcement. Yet, there is a need to complement ongoing analyses of administrative arrangements with a nuanced consideration of how relations of power and social framings influence the discourse on resilience and law. On the surface, rules and processes of the EU Water Directive may seem 'adaptive' and may even foster resilience of the system. Ultimately, however, compliance and enforcement hinges on individual agency, perceptions about the legitimacy of the Directive and the extent to which it reflects the values of those over whom it has influence.

\footnotetext{
${ }^{1}$ University of Waterloo
} 
Green et al.'s review of the EU Water Framework Directive provides an interesting window on the challenge of creating legal and regulatory frameworks positioned to be adaptive in the context of change, while also meeting the criteria of robustness and legitimacy. As their analysis of the Water Directive reveals, finding a fit between regulatory flexibility and sufficient enforcement is no simple matter, all the more so in the absence of relevant analogues or precedents.

\section{LITERATURE CITED}

Green, O. O., A. S. Garmestani, H. F. M. W. Van Rijswick, and A. M. Keessen. 2013. EU water governance: striking the right balance between regulatory flexibility and enforcement? Ecology and Society 18(2): 10. http://dx.doi.org/10.5751/ ES-05357-180210

Walker, B., S. Carpenter, J. Anderies, N. Abel, G. Cumming, M. Janssen, L. Lebel, J. Norberg, G. D. Peterson, and R. Pritchard. 2002. Resilience management in social-ecological systems: a working hypothesis for a participatory approach. Conservation Ecology 6(1): 14. [online] URL: http://www. consecol.org/vol6/iss1/art14.

Walker, B., C. S. Holling, S. R. Carpenter, and A. Kinzig. 2004. Resilience, adaptability and transformability in socialecological systems. Ecology and Society 9(2): 5. [online] URL: http://www.ecologyandsociety.org/vol9/iss2/art5/.

Responses to this article can be read online at:

http://www.ecologyandsociety.org/issues/responses.php/5611 